\title{
A Tribute to Hans Dietrich Polaschegg
}

Roughly 60 years ago, we witnessed the birth of clinical dialysis. Since then we have celebrated many milestones and successes, as well as struggled with challenges. The first challenge, obviously, was in developing a system to cleanse uremic blood, which was made possible with the advent of dialysis in the 1950s. With the possibility to treat patients with end-stage renal disease a reality, the next obstacle was to make it available to the masses. By the end of the 1960s, this challenge was being met and a large population of uremic patients could receive dialysis treatment thanks to new technological advances. The trend continued in the 1970s, a decade which saw dialysis treatment become more reliable, comfortable, and safer with the advent of new blood pumps, accurate dialysis fluid modules, and disposable hemodialyzers. Treatment time could also be drastically cut from 12 to $4 \mathrm{~h}$ per session.

By the mid-1980s, however, some significant challenges began to appear, especially concerning problems associated with long-term dialysis. One of these was hemodialysis-related amyloidosis, which highlighted the need for biocompatible high-flux membranes, pure or ultrapure dialysate, and personalized treatment. Technological advances, like the ultrafiltration control system for dialysis machines, and new approaches such as 'treatment personalization' and 'treatment profiling' helped to meet this new challenge.

In looking back on this history of overcoming difficulties and mastering new challenges, one cannot help but to reflect upon Hans Dietrich Polaschegg (1942-2012), one of the major pioneers in the field of hemodialysis, who always advised against believing that there is nothing left to be done. After all, although challenges have been solved, just as many are probably right around the corner. And of course, the twenty-first century has already presented its first challenges. The medical community is having to tackle the problem of limited resources as health care plans struggle to contain costs across the board and emerging countries try to offer dialysis to their renal patients.

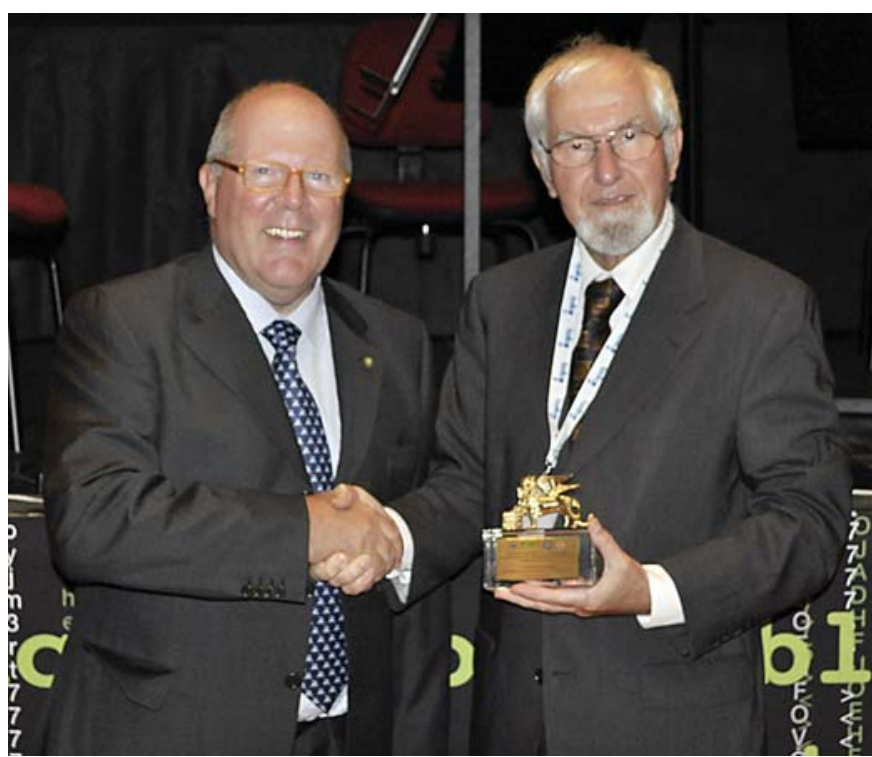

Claudio Ronco and Hans Dietrich Polaschegg

Hans Dietrich Polaschegg was a major player in the field of hemodialysis and in many ways responsible for dialysis as we know it. He held over 100 patents, many of which were related to renal technology, and played a leading role in the development of technical and safety standards for dialysis equipment. After retiring as Head of Research and Development at Fresenius, Hans continued his research at home in his garage, at the University of Graz, and as a consultant. I had the privilege and honor of calling Hans a friend, and his charismatic personality had a strong impact on my professional, scientific, and private life. For this reason, I have been requested to deliver a memorial lecture and prepare a paper for this special issue of Blood Purification to pay tribute to and honor the memory of Hans Dietrich Polaschegg, his scientific knowledge, and his innovative spirit.

Claudio Ronco, Vicenza

\begin{tabular}{ll}
\hline KARGER & (c) 2013 S. Karger AG, Basel \\
0253-5068/13/0353-0007\$38.00/0 \\
$\begin{array}{ll}\text { Fax +41 61 } 3061234 & \text { Accessible online at: } \\
\text { www.karger.com } & \text { www.karger.com/bpu }\end{array}$
\end{tabular}

